Article

\title{
Antioxidant and Antimicrobial Activities of the Essential Oil of Achillea millefolium L. Grown in France
}

\author{
Chaker El-Kalamouni ${ }^{1,2, *}$, Petras Rimantas Venskutonis ${ }^{3}$, Bachar Zebib ${ }^{4}$, Othmane Merah ${ }^{1}$, \\ Christine Raynaud ${ }^{1}$ and Thierry Talou ${ }^{1}$
}

1 Laboratoire de Chimie Agro-Industrielle, Université Fédérale de Toulouse Midi-Pyrénées, INP-ENSIACET, Toulouse 31030, France; Othmane.Merah@ensiacet.fr (O.M.); Christine.raynaud@ensiacet.fr (C.R.);

Thierry.Talou@ensiacet.fr (T.T.)

2 Unité Mixte 134 Processus Infectieux en Milieu Insulaire Tropical, Université de la Réunion, INSERM U1187, CNRS UMR 9192, IRD UMR 249. Plateforme Technologique CYROI, Sainte Clotilde 97490, France

3 Department of Food Technology, Kaunas University of Technology, Radvilènu pl. 19, LT-50254 Kaunas, Lithuania; rimas.venskutonis@ktu.lt

4 Laboratoires Agronutrition SAS, 3 allée de l'Orchidée Carbone 31390, France; b.zebib@agro-nutrition.fr

* Correspondence: chaker.el-kalamouni@univ-reunion.fr; Tel.: +262-262-938822; Fax: +262-262-938801

Academic Editor: Eleni Skaltsa

Received: 20 February 2017; Accepted: 15 May 2017; Published: 19 May 2017

\begin{abstract}
Background: This study aimed to examine the composition of essential oil (EO) of A. millefolium aerial parts wild plant grown in France and evaluate its antioxidant, antibacterial, and antifungal activities. Methods: GC-MS was used to identify the chemical composition of EO. Antioxidant activity (AA) of EO was evaluated by Oxipres method. Antimicrobial activity of EO was evaluated by Agar-well diffusion and a broth microdilution assay. Results: Forty-three volatile compounds were identified. Major compounds were camphor $(12.8 \%)$, germacrene-D $(12 \%),(E)$-nerolidol (7.3\%), sabinene (6.7\%), (E)-p-mentha-2,8-dien-1-ol (4.5\%), and 1,8-cineole (4\%). EO shows strong AA against Sunflower oil oxidation. Additionally, an inhibitory effect against microbial organisms (bacteria and fungi) was found. Conclusion: The EO composition of A. millefolium chemotype located in France was studied. The EO of the A. millefolium wild plant grown in France is quite an effective antioxidant in sunflower oil oxidation; it also possesses inhibitory effects against famous bacteria and fungi.
\end{abstract}

Keywords: Achillea millefolium L.; essential oil; antioxidant; antimicrobial activity

\section{Introduction}

The global interest in food preservation has been recently greatly increased due to high economic costs of deterioration and poisoning of food products through lipid oxidation as well as food pathogens. Currently, there is a growing interest in prolonging shelf-life and the safety of food using natural antioxidant and antimicrobial compounds. This aspect assumes particular relevance due to an increased resistance of some bacterial and fungi strains to the most common antibiotics and antimicrobial synthetic agents [1]. Essential oils or some of their components have been largely used in perfumes, in sanitary products, in dentistry, in agriculture, as food preservers and additives, and as naturals remedies [2].

Mostly found in Europe, Asia, and temperate regions including North America, the Achillea genus, belonging to Asteraceae family, is represented by about 85 species [3]. A. millefolium (common yarrow) has been used in many applications such as medicine, veterinary science, and cosmetics [4]. The flowering herbs were reported as possessing tonic, antispasmodic, vulnerary, and diaphoretic 
activities, among others, and therefore is recommended for colds, flatulence, hysteria, and rheumatism treatments [5]. The chemical composition of A. millefolium oils from Québec [6], India [7], Turkey [3], Iran [8], and European countries (Macedonia, Italy, Lithuania, Hungary, Greece, Moldavia, Latvia, Germany Estonia, Belgium, France, Russia, Armenia, Spain, and Bulgaria) [9-14] has been reported in previous studies. However, the reports on antioxidant and antimicrobial properties of A. millefolium EO are rather scarce. Considering remarkable chemical polymorphism, which is characteristic of many essential oil-bearing plants, it is of interest to determine the chemical composition and biological activities of plant varieties growing in different regions.

Therefore, the aim of this study was to investigate the antioxidant, the antibacterial, and the antifungal activities of EO of A. millefolium aerial parts of French origin. Additionally, this study aims to inspect the chemical profile of $A$. millefolium EO grown in France and to compare this profile to previous studies where the EO of A. millefolium was obtained from other countries.

\section{Materials and Methods}

\subsection{Plant Material}

The aerial parts of wild Achillea millefolium L. plant were picked in May 2008 at the bloom stage from Toulouse $\left(43^{\circ} 36^{\prime} 01^{\prime \prime} \mathrm{N}, 1^{\circ} 25^{\prime} 58^{\prime \prime} \mathrm{E}\right)$, France. The voucher specimens were deposited in the Herbarium of the Pharmacognosy Laboratory, Faculty of the Pharmaceutical Sciences, Universite de Toulouse III, N (AST. 251 (2008) (I.F.)).

\subsection{EO Extraction}

Five hundred grams (500 g) of fresh areal plant parts at flowering stage were blended with $4 \mathrm{~L}$ of distilled water and submitted to water-distillation in a modified Clevenger-type apparatus for $3 \mathrm{~h}$. After distillation, the collected oil was isolated from the water and dried over sodium sulfate (water free). Six replicate distillations were performed and the EO was stowed at $4{ }^{\circ} \mathrm{C}$ before analysis.

\subsection{Gas Chromatography Coupled with Mass Spectrometry Analysis (GC-MS)}

The EO was solvated in $n$-pentane (Sigma-Aldrich, St Quentin Fallavier, France) $(10 \% v / v)$ and construed on a Clarus 500 (Perkin Elmer Instruments, Shelton, USA) gas chromatograph outfit with a fused-silica capillary column HP-5MS (5\% diphenyl 95\% dimethyl polydimethylsiloxane, $30 \mathrm{~m}$ length, $0.25 \mathrm{~mm}$ id, $0.25 \mu \mathrm{m}$ film thickness (J\&W scientific, Folsom, CA). Flame ionization detector (FID) (Perkin Elmer Instruments, Shelton, CT, USA) was used. The importer gas was helium ( $1.3 \mathrm{~mL} / \mathrm{min}$ flow). The injection volume was $0.5 \mu \mathrm{L}$. Injector temperature was $250{ }^{\circ} \mathrm{C}$ and under split mode at a ratio of 1:5. The temperature of FID was $250{ }^{\circ} \mathrm{C}$. The furnace temperature was programmed at $60^{\circ} \mathrm{C}$ for $5 \mathrm{~min}$, grated to $250^{\circ} \mathrm{C}$ at $5{ }^{\circ} \mathrm{C} / \mathrm{min}$ and maintained at $250{ }^{\circ} \mathrm{C}$ for $5 \mathrm{~min}$. The identification of compounds was built on retention indices (RI) qualified to C5-C18 n-alkanes (Sigma-Aldrich, St Quentin Fallavier, France) and available literature data $[15,16]$ and on computer matching of obtained fragments from mass spectrum with those present in NIST 2008 and WILEY 275L MS libraries. Results are the mean from at least three independent experiments performed in six replicates.

\subsection{Evaluation of $A A$ of $E O$ by the Oxipres Method}

The preparation of samples is obtained by mixing sunflower oil with $0.05 \%$ or $0.1 \%$ or $0.2 \%$ amounts of EO. In the Oxipres apparatus (Mikrolab, Aarhus, Denmark), $5 \mathrm{~g}$ of sunflower oil were placed inside a reactor tube heated at $110{ }^{\circ} \mathrm{C}$ under an oxygen pressure of 5 bar. The variations in pressure occurred were recorded. The control sample not contain additive. After the addition of each dose of EO, all variations of induction period $(I P)$ of sunflower oil were collected with time (h). 3,5-di-tert-4-butylhydroxytoluene (BHT) (Sigma-Aldrich, St. Quentin Fallavier, France) was used 
as a positive control. The AA of $\mathrm{EO}$ and the protection factor $(P F)$ variations of sunflower oil were determined by Equations (1) and (2):

$$
\begin{gathered}
P F=\frac{I P_{x}}{I P_{k}} \\
A A=\frac{I P_{x}-I P_{k}}{I P_{B H T}-I P_{k}}
\end{gathered}
$$

where $I P_{X}$ is the induction period of the sample with additive, $I P_{K}$ is the induction period of the sample without additive, $I P_{B H T}$ is the induction period of the sample with synthetic antioxidant BHT.

\subsection{Assessment of Antibacterial Effect of EO}

Two types of bacteria were tested; (1) Gram-positive-Bacillus subtilis ATCC6633, Bacillus cereus ATCC10876, Staphylococcus aureus ATCC25923, and Staphylococcus epidermidis ATCC12228-and (2) Gram-negative pathogens Salmonella typhimurium ATCC14028, Salmonella typhimurium DS88, Salmonella enteritidis ATCC13076, Salmonella agona ATCC43889, and Escherichia coli ATCC25922 were kindly donated by Dr. A. Šarkinas (Food Institute of Kaunas University of Technology, Kaunas, Lithuania).

\subsubsection{Agar Well Diffusion Method}

Antibacterial assay was carried using agar well diffusion. The bacteria were cultured for $18 \mathrm{~h}$ at $37^{\circ} \mathrm{C}$ on the slant agar (Oxoid, CM325). Adjustment of washed cell bacteria was carried out according to McFarland No. 0.5 standard [17]. Into $90 \mathrm{~mm}$ diameter Petri plates, $10 \mathrm{~mL}$ of each bacteria culture were pipetted. To fill the wells ( $6 \mathrm{~mm}$ in diameter), agar was pressed with $10 \mu \mathrm{L}$ of ethanolic solutions contained $5 \mu \mathrm{g} / \mathrm{mL}$ of EO. Ethanol was used to dissolve the oil for negative controls preparation. Susceptibility test disc Ceftazidime/Clavulanic Acid, CAZ-CLA, 30/10 $\mu \mathrm{g}$ (BBL, CAZ/CLA, 231753) was used as a positive control. Incubation time of plates was $24 \mathrm{~h}$ at $37^{\circ} \mathrm{C}$. Antibacterial effect was assessed by the diameter of clear zones developed around wells. Results are the mean $( \pm$ SEM) from at least three independent experiments performed in triplicates.

\subsubsection{Determination of Minimum Inhibitory Concentrations (MICs)}

MIC was determined on the base of a microdilution broth susceptibility test [18]. All tests were made in Mueller Hinton Broth (MHB; BBL) (Microbiology Systems, Inc., Cockeysville, MD, USA) supplemented with Tween 80 detergent (Fisher, Illkirch, France) to achieve a final concentration of $0.5 \%(v / v)$. The culture of bacteria was made overnight at $37{ }^{\circ} \mathrm{C}$ in Mueller Hinton Agar, MHA (Sigma-Aldrich, St. Quentin Fallavier, France). To obtain a final density of $5 \times 10^{5} \mathrm{cfu} / \mathrm{mL}$, tests were hanging in MHB. To obtain a final concentration values reaching from 0-1000 $\mu \mathrm{g} / \mathrm{mL}$ of EO in MHB, dilutions were prepared in a 96-well microplates (Sarstedt, Nümbrecht, Germany). Growth control was (MHB + Tween 80 ) and sterility control was (MHB + Tween 80 + sample). The microplates were smoldered at $37^{\circ} \mathrm{C}$ during $24 \mathrm{~h}$. A microplate reader (Multiskan Ascent, Thermo Fisher Scientific, Loughborough, UK) was used to the bacterial growth determination. The reading absorbance was $620 \mathrm{~nm}$. The MICs represent the concentrations of EO causing at least $50 \%$ growth inhibition of the bacterial strains. Results are the mean $( \pm$ SEM) from at least three independent experiments performed in triplicates.

\subsection{Assessment of Antifungal Activity of EO}

The fungi samples were obtained from the Leibniz Institute (DSMZ, Braunschweig, Germany). The fungal species tested in this study were Botrytis cinerea DSM-5144, Rhizopus stolonifer DSM-2194, Verticillium dahliae DSM-11938, Aspergillus niger DSM-1957, and Colletotrichum gloeosporioides DSM-62146. The culture of fungal species was made on Potato-Dextrose-Agar (PDA) slants purchased from VWR (Strasbourg, France). The storage temperature was $4{ }^{\circ} \mathrm{C}$. After 10 days of culture, the fungi spore were 
obtained, then blended with sterile distilled water to get a spore suspension of $1 \times 10^{8}$ spore $/ \mathrm{mL}$. The concentrations of EO solutions were reached from 0.1 to $3 \mathrm{mg} / \mathrm{mL}$. The disc diffusion method [16] was adopted to evaluate the antifungal activity. Five microliters $(5 \mu \mathrm{L})$ of EO was used. Inhibition percent was obtained by Equation (3):

$$
\text { Inhibition }(\%)=\frac{1-\text { radial growth of treatment }}{\text { radial growth of control }} \times 100 \text {. }
$$

MIC value was obtained from the equation of the line (\% inhibition against concentration). The lower MIC value shows better antifungal activity. All antifungal results are the mean $( \pm$ SEM $)$ from at least three independent experiments performed in triplicates.

\section{Results and Discussion}

\subsection{Composition of EO}

The yellow greenish EO isolated from French A. millefolium aerial parts possessed a strong characteristic odor. The EO yield was $0.07 \%$ (Fresh weight), which is $5 \mathrm{t}$ higher than reported for Indian origin (0.014\%) [5], $3 \mathrm{t}$ lower than in Canadian samples (0.21\%) [6].

Forty-three compounds were identified in A. millefolium EO amounting $96.3 \%$ of the total EO (Table 1). Oxygenated monoterpenes constituted the major part of the EO (40.7\%), with camphor $(12.8 \%)$, trans-chrysantenyl acetate (6.6\%), terpinen-4-ol (4.70\%), (E)-p-mentha-2,8-dien-1-ol (4.5\%), and 1,8-cineole $(4.0 \%)$ being its main components. Other quantitatively important fractions were hydrocarbon sesquiterpenes $(17 \%)$ and oxygen-containing sesquiterpenes $(19.5 \%)$, germacrene-D $(12.0 \%)$ and $(E)$-nerolidol $(7.3 \%)$ being the main components. The monoterpene part corresponded only to $15 \%$, sabinene $(6.7 \%)$ and $\beta$-pinene $(3.4 \%)$ being its main constituents.

It may be observed that the main components of $A$. millefolium analyzed in our study to some extent were comparable to those previously reported [7-12]. However, the content of such components as hexane-2,3-dione, hex-3-en-1-ol, methyl hexanoate, (E)-p-mentha-2,8-dien-1-ol, (Z)- $p$-menthan-2-one, thymol acetate, $(E)$-methyl isoeugenol, $\beta$-cedrene epoxide, and patchouli alcohol in the oil of A. millefolium analyzed in our study was considerably higher than in the previously studied yarrow oils. Camphor (up to 20\%), $\alpha$ and $\beta$-thujones (up to $26.8 \%$ ), 1,8-cineole (up to $20.3 \%$ ), artemisia ketone (up to $10.1 \%$ ), and chamazulene (up to $0.8 \%$ ) were reported in A. millefolium oil from France [12], but the content of these compounds in our study was rather different; it contained $12.8 \%$ camphor, $4.5 \%$ (E)-p-mentha-2,8-dien-1-ol, 4.7\% terpinen-4-ol, 4.0\% 1,8-cineole, and 1.8\% borneol, whereas artemisia ketone, thujones, and chamazulene were not detected.

A completely different $A$. millefolium chemotype was reported in the Saguenay region around Quebec in Canada where the $\beta$-thujone was the main compound (13.8\%) [6]. The sesquiterpene alcohols spathulenol, (Z)-nerolidol, $\alpha$-bisabolol, and $(E, E)$-farnesol were dominant constituents in the A. millefolium oil from Iran [8]. These results confirm that the chemical polymorphism is a characteristic feature of yarrow. The variations in the chemical profile of the A. millefolium oil as a consequence of ontogenesis and organic differentiation were recently noted [19]. The influence of ecological factors (climate, altitude, association, nutrients, etc.) seems to be an important factor; in addition to the like chemotype, variations in $\mathrm{EO}$ chemical composition could exist. 
Table 1. Chemical composition of EO of wild Achillea millefolium L. (aerial parts) from Toulouse region, France.

\begin{tabular}{|c|c|c|c|c|c|}
\hline No. & Compounds & $\mathrm{RI}^{\mathrm{a}}$ & $\mathrm{RI}^{\mathrm{b}}$ & $(\%)^{c}$ & $\mathrm{RSD}^{\mathrm{d}}$ \\
\hline 1 & Hexane-2,3-dione & 800 & 790 & 0.1 & 6.39 \\
\hline 2 & (E)-Hex-3-en-1-ol & 849 & 854 & 0.2 & 7.15 \\
\hline 3 & Methyl hexanoate & 926 & 927 & 0.2 & 5.68 \\
\hline 4 & $\alpha$-Pinene & 935 & 939 & 1.7 & 6.93 \\
\hline 5 & Camphene & 952 & 954 & 1.6 & 8.35 \\
\hline 6 & Sabinene & 974 & 975 & 6.7 & 7.31 \\
\hline 7 & $\beta$-Pinene & 981 & 979 & 3.4 & 9.66 \\
\hline 8 & $\alpha$-Terpinene & 1018 & 1017 & 0.7 & 6.43 \\
\hline 9 & $p$-Cymene & 1025 & 1025 & 0.8 & 8.20 \\
\hline 10 & 1,8-Cineole & 1034 & 1031 & 4.0 & 8.89 \\
\hline 11 & $\gamma$-Terpinene & 1058 & 1060 & 1.7 & 7.93 \\
\hline 12 & Terpinolene & 1086 & 1089 & 0.4 & 6.39 \\
\hline 13 & Linalool & 1099 & 1097 & 1.8 & 7.15 \\
\hline 14 & Nonanal & 1103 & 1101 & 0.6 & 5.68 \\
\hline 15 & (E)-p-Mentha-2,8-dien-1-ol & 1119 & 1123 & 4.5 & 6.93 \\
\hline 16 & (Z)-p-Mentha-2,8-dien-1-ol & 1138 & 1138 & 0.3 & 8.35 \\
\hline 17 & trans-Pinocarveol & 1144 & 1139 & 0.8 & 5.30 \\
\hline 18 & Camphor & 1151 & 1146 & 12.8 & 4.85 \\
\hline 19 & Borneol & 1163 & 1169 & 1.8 & 4.83 \\
\hline 20 & Terpinen-4-ol & 1183 & 1177 & 4.7 & 4.10 \\
\hline 21 & (Z)-p-Menthan-2-one & 1198 & 1196 & 1.5 & 4.56 \\
\hline 22 & trans-Chrysanthenyl acetate & 1228 & 1238 & 6.6 & 1.76 \\
\hline 23 & Bornyl acetate & 1285 & 1289 & 1.2 & 5.60 \\
\hline 24 & Thymol acetate & 1355 & 1352 & 0.7 & 6.27 \\
\hline 25 & $\alpha$-Copaene & 1377 & 1377 & 0.5 & 5.30 \\
\hline 26 & (E)-Caryophyllene & 1415 & 1419 & 1.7 & 4.85 \\
\hline 27 & cis- $\beta$-Farnesene & 1447 & 1443 & 0.8 & 4.83 \\
\hline 28 & Germacrene-D & 1483 & 1485 & 12.0 & 3.97 \\
\hline 29 & (E)-Methyl isoeugenol & 1496 & 1492 & 1.0 & 3.72 \\
\hline 30 & $\gamma$-Cadinene & 1513 & 1514 & 0.4 & 3.31 \\
\hline 31 & $\delta$-Cadinene & 1517 & 1523 & 1.2 & 4.17 \\
\hline 32 & $\alpha$-Calacorene & 1542 & 1546 & 0.4 & 3.60 \\
\hline 33 & Elemol & 1553 & 1550 & 1.6 & 3.95 \\
\hline 34 & (E)-Nerolidol & 1559 & 1563 & 7.3 & 3.36 \\
\hline 35 & Caryophyllenyl alcohol & 1574 & 1572 & 0.8 & 4.00 \\
\hline 36 & Spathulenol & 1584 & 1578 & 2.0 & 3.80 \\
\hline 37 & Caryophyllene oxide & 1596 & 1583 & 1.9 & 4.34 \\
\hline 38 & Viridiflorol & 1610 & 1593 & 1.8 & 4.31 \\
\hline 39 & $\beta$-Cedrene epoxide & 1625 & 1623 & 0.5 & 4.62 \\
\hline 40 & $\beta$-Eudesmol & 1654 & 1651 & 1.1 & 2.51 \\
\hline 41 & Cedr-8(15)-en-10-ol & 1659 & 1652 & 0.2 & 3.12 \\
\hline 42 & Patchouli alcohol & 1669 & 1658 & 0.8 & 3.90 \\
\hline 43 & $\alpha$-Bisabolol & 1683 & 1686 & 1.5 & 1.03 \\
\hline \multirow[t]{6}{*}{ Total } & compounds & & & 96.30 & \\
\hline & Oxygenated monoterpenes & & & 40.70 & \\
\hline & Oxygenated sesquiterpenes & & & 19.5 & \\
\hline & Hydrocarbon sesquiterpenes & & & 17 & \\
\hline & Monoterpenes & & & 15 & \\
\hline & Other & & & 4.1 & \\
\hline
\end{tabular}

a calculated retention indices; ${ }^{\mathrm{b}}$ literature values of retention indices $[15,16] ;{ }^{\mathrm{c}}$ relative $\%$ of the compounds gated from FID area percent data; ${ }^{d}$ RSD: Relative Standard Deviation $(n=6)$.

\subsection{AA of EO Against Sunflower Oil Oxidation}

Plant oils containing sensitive to oxidative degradation unsaturated fatty acids have been widely used as substrates for testing AA. The ability of A. millefolium EO to protect the sunflower oil was evaluated by comparing with synthetic antioxidant BHT in Oxipres apparatus. The effect of additives was expressed as a protection factor (PF) indicating the increase in sunflower oil stability (Table 2). The addition of $0.2 \%$ of $A$. millefolium EO increased the stability of sunflower oil about $1.5 \mathrm{t}$ (the IP of sunflower oil without additives was $2.9 \mathrm{~h}$ ). A. millefolium oil prolonged the IP of sunflower oil oxidation depending on the concentration; the highest concentration of additive $(0.2 \%)$ was more effective than BHT applied at $0.02 \%$ (Table 2). AA of other EO plant species in sunflower oil was previously evaluated by the Oxipres method; for instance, Calamintha grandiflora applied at $0.2 \%$ 
demonstrated PF of 1.63 [20]. In conclusion, A. millefolium EO stabilized the oxidation of sunflower oil. This stability of oil rose with the added amounts of EO.

Table 2. AA of Achillea millefolium L. essential oil evaluated in sunflower oxidation test (Oxipres method).

\begin{tabular}{cccccc}
\hline Additive & $\begin{array}{c}\text { Concentration } \\
\mathbf{\%}\end{array}$ & $\begin{array}{c}\text { Protection } \\
\text { Factor (PF) }^{\mathbf{a}}\end{array}$ & $\begin{array}{c}\text { Antioxidant } \\
\text { Activity (AA) }^{\mathbf{b}}\end{array}$ & $\begin{array}{c}\text { Induction } \\
\text { Period (IP) }^{\mathbf{c}}\end{array}$ & RSD $^{\mathbf{d}}$ \\
\hline Without additive & 0.00 & 1.00 & - & 2.90 & 0.30 \\
BHT & 0.02 & 1.47 & 1.00 & 4.26 & 0.50 \\
Essential oil & 0.20 & 1.71 & 1.51 & 4.96 & 0.50 \\
Essential oil & 0.10 & 1.29 & 0.62 & 3.74 & 1.00 \\
Essential oil & 0.05 & 1.17 & 0.36 & 3.39 & 0.40 \\
\hline
\end{tabular}

a $\overline{\mathrm{PF}}=\mathrm{IP}_{\text {(sample with additive) }} / \mathrm{IP}_{\text {(sample without additive) }}{ }^{\mathrm{b}}$ AA was determined by comparison with the reference (BHT $0.02 \%) ;{ }^{c}$ IP = time when the pressure start to reduce suddenly; ${ }^{\mathrm{d}}$ RSD: the relative standard deviation $(n=3)$.

\subsection{Antibacterial Activity of $E O$}

Antibacterial effect of EO was evaluated in vitro against nine pathogenic bacteria species (Table 3). Gram-positive bacteria were more delicate to the EO than Gram-negative bacteria. B. cereus was the most susceptible bacteria to A. millefolium oil at the applied concentrations ( 5 and $10 \mu \mathrm{g} / \mathrm{mL}$ ). The smallest inhibition zones were obtained in S. typhimurium and S. agona cultures while St. epidermidis, S. enteritidis, and E. coli were resistant against all concentrations of A. millefolium oil. MIC for B. cereus and St. aureus were 100 and $120 \mu \mathrm{g} / \mathrm{mL}$, respectively; while the MIC for B. subtilis was $310 \mu \mathrm{g} / \mathrm{mL}$. Among the Gram-negative tested bacteria, a remarkable antibacterial effect was observed only for S. typhimurium and S. agona with their respective MIC values 2000 and $1000 \mu \mathrm{g} / \mathrm{mL}$. The effect of A. millefolium oil from Turkey [3] was also tested against St. aureus and B. cereus; it was found that the MIC was $72 \mathrm{mg} / \mathrm{mL}$, which is remarkably higher than the MIC of A. millefolium oil measured in our study. As was shown, the composition of $A$. millefolium oils from various locations may be rather different. The properties and the content of individual constituents may have an important power on the antibacterial effect of oil against different bacteria species. For instance, sabinene, 1,8-cineole, and camphor, which were abundant in A. millefolium oil studied in this work, are well-known natural chemicals with antibacterial potentials [21]. The EO also studied in our work also contained $12 \%$ of germacrene-D and $7.3 \%$ of $(E)$-nerolidol, which were absent in the Turkish oil. The antibacterial activities of germacrene-D and $(E)$-nerolidol were previously reported as well [22].

Table 3. Antibacterial activity of Achillea millefolium L. EO against bacterial pathogens.

\begin{tabular}{|c|c|c|c|c|c|}
\hline \multirow[t]{3}{*}{ Microorganism } & \multirow[t]{3}{*}{ Gram +l- } & \multicolumn{3}{|c|}{ Inhibition Zone Diameter $(\mathrm{mm})^{a}$} & \multirow{2}{*}{$\begin{array}{c}\text { Essential Oi } \\
\text { MIC }^{\mathrm{d}}\end{array}$} \\
\hline & & \multicolumn{2}{|c|}{ Essential Oil $^{b}$} & Antibiotic $^{c}$ & \\
\hline & & $10 \mu \mathrm{g} / \mathrm{mL}$ & $5 \mu \mathrm{g} / \mathrm{mL}$ & $(30 / 10) \mu \mathrm{g}$ & $\mu \mathrm{g} / \mathrm{mL}$ \\
\hline B. subtilis & G+ & $11.0 \pm 0.2$ & $8.6 \pm 0.1$ & $16.8 \pm 0.1$ & $310 \pm 20$ \\
\hline B. cereus & G+ & $13.6 \pm 0.2$ & $10.7 \pm 0.2$ & $29.0 \pm 0.2$ & $100 \pm 10$ \\
\hline St. aureus & G+ & $12.8 \pm 0.1$ & $9.1 \pm 0.2$ & $21.0 \pm 0.3$ & $120 \pm 12$ \\
\hline St. epidermidis & G+ & $\mathrm{na}^{\mathrm{e}}$ & na & $25.8 \pm 0.1$ & na \\
\hline S. typhimurium & G- & $9.2 \pm 0.2$ & na & $31.2 \pm 0.3$ & $2000 \pm 40$ \\
\hline S. typhimurium & G- & na & na & $34.0 \pm 0.1$ & na \\
\hline S. enteritidis & G- & na & na & $32.2 \pm 0.3$ & na \\
\hline S. agona & G- & $10.4 \pm 0.4$ & $9.1 \pm 0.3$ & $20.8 \pm 0.3$ & $1000 \pm 40$ \\
\hline E. coli & G- & na & na & $26.4 \pm 0.2$ & na \\
\hline
\end{tabular}

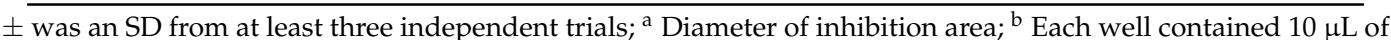
ethanolic solution of essential oil (10 and $5 \mu \mathrm{g} / \mathrm{mL}) ;{ }^{c}$ Ceftazidime/Clavulanic Acid (30/10 $\mu \mathrm{g} /$ disc) was a positive control; ${ }^{\mathrm{d}}$ MIC: minimum inhibitory concentration (values in $\mu \mathrm{g} / \mathrm{mL}$ ); ${ }^{\mathrm{e}}$ na: no activity. 


\subsection{Antifungal Activity of EO}

EO of A. millefolium showed remarkable antifungal activity against all plant fungi tested (Table 4) at $5 \mu \mathrm{L}$ (1000 ppm/disc). It exhibited an inhibitory result on the development of $R$. stolonifer $(65.7 \%)$ V. dahliae (56.3\%), C. gloeosporioides (60.9\%), Botrytis cinerea (50.8\%), and Aspergillus niger (40.7\%). The inhibitory effects might be related to the presence of mono- $(55.7 \%)$ and sesquiterpenes $(36.5 \%)$ in the EO [23].

Table 4. Antifungal activity of Achillea millefolium L. EO ( $5 \mu \mathrm{L}$ corresponding to $1000 \mathrm{ppm} / \mathrm{disc})$.

\begin{tabular}{ccc}
\hline Fungal Strain & \multicolumn{2}{c}{ Mycelial Growth Inhibition $^{\text {a }}$} \\
\hline \multicolumn{2}{c}{ Essential Oil } \\
\hline mm & $\%$ \\
\hline R. stolonifer & $11.5 \pm 1.4$ & $65.7 \pm 2.2$ \\
V. dahliae & $10.1 \pm 1.4$ & $65.3 \pm 2.6$ \\
C. gloeosporioides & $12.2 \pm 1.4$ & $60.9 \pm 2.5$ \\
B. cinerea & $18.4 \pm 1.4$ & $50.8 \pm 3.8$ \\
A. niger & $24.8 \pm 0.8$ & $40.7 \pm 0.5$ \\
\hline
\end{tabular}

\pm was an SD from at least three independent trials; ${ }^{a}$ expressed in $\mathrm{mm}$ from radial evolution; \% of radial growth inhibition.

The MICs defined as the deepest concentrations of the EO that allows for full progress inhibition of $R$. stolonifer, V. dahliae, C. gloeosporioides, B. cinerea, and A. niger were 1.6, 3.1, 3.4, 3.6, and $4.7 \mathrm{mg} / \mathrm{mL}$, respectively (Table 5). R. stolonifer was discovered to be the greatest sensitive fungal pathogens towards the A. millefolium EO.

Table 5. Minimum inhibitory concentration (MIC) of A. millefolium L. EO.

\begin{tabular}{cc}
\hline Fungal Strain & MIC $^{\text {a }}$ \\
\hline & Oil \\
Rhizopus stolonifer DSM-2194 & 1.6 \\
Verticillium dahliae DSM-11938 & 3.1 \\
Colletotrichum gloeosporioides DSM-62146 & 3.4 \\
Botrytis cinerea DSM-5144 & 3.6 \\
Aspergillus niger DSM-1957 & 4.7 \\
\hline${ }^{a}$ MIC, minimum inhibitory concentration (values in $\mathrm{mg} / \mathrm{mL}$ ).
\end{tabular}

\section{Conclusions}

In conclusion, the EO of A. millefolium, growing wild in the Midi-Pyrenees region, possesses quite a unique chemical composition as compared with the oil composition of the same species reported in previously published studies. $\alpha$-Pinene, sabinene, camphor, trans-chrysanthenyl acetate, cyclocitral isomers, and germacrene $\mathrm{D}$ were the main components indicating an individual chemotype of the studied plant sample. The $\mathrm{EO}$ of A. millefolium was quite an effective antioxidant preserving oxidation of sunflower oil; it also possessed inhibitory effects against tested bacteria and fungi. The EO of A. millefolium growing wild in the Toulouse region show a varied interval of activities against plant fungi. In our study, it has become clear that the $\mathrm{EO}$ of A. millefolium possesses an important ability to intensely inhibit the development of $B$. cinerea with other plant fungi tested in this work. These results provide preliminary support for the potential uses of A. millefolium essential oil for the prolongation of shelf-life and the safety of food preparations possessing specific odor properties, as well as antioxidant and antimicrobial activities. 
Acknowledgments: This study was performed in the framework of bilateral French-Lithuanian program "Gilibert" (grant $n^{\circ} 19981 W G / 2009 / 2010$ ), supported by Research Council of Lithuania (grant no. TAP-47/2010 and TAP-11/2010) and the French Research Minister.

Author Contributions: C.R. and T.T. conceived the study, C.E.-K., P.R.V., C.R. and T.T. designed the experiments, B.Z., O.M. and C.E.-K. conducted the experiments, C.R., P.R.V., C.E.-K., B.Z., O.M. and T.T. analyzed the results, B.Z. and C.E.-K. wrote the manuscript, P.R.V. and T.T. acquired the funding.

Conflicts of Interest: The authors declare no conflict of interest.

\section{References}

1. Bajpai, V.K.; Rahman, A.; Kang, S.C. Chemical composition and inhibitory parameters of essential oil and extracts of nandina domestica thunb. to control food-borne pathogenic and spoilage bacteria. Int. J. Food Microbiol. 2008, 125, 117-122. [CrossRef] [PubMed]

2. Bakkali, F.; Averbeck, S.; Averbeck, D.; Idaomar, M. Biological effects of essential oils-A review. Food Chem. Toxicol. 2008, 46, 446-475. [CrossRef] [PubMed]

3. Candan, F.; Unlu, M.; Tepe, B.; Daferera, D.; Polissiou, M.; Sökmen, A.; Akpulat, H.A. Antioxidant and antimicrobial activity of the essential oil and methanol extracts of achillea millefolium subsp. millefolium afan. (asteraceae). J. Ethnopharmacol. 2003, 87, 215-220. [CrossRef]

4. Tadić, V.; Arsić, I.; Zvezdanović, J.; Zugić, A.; Cvetković, D.; Pavkov, S. The estimation of the traditionally used yarrow (Achillea millefolium L. Asteraceae) oil extracts with anti-inflamatory potential in topical application. J. Ethnopharmacol. 2017, 199, 138-148. [CrossRef] [PubMed]

5. Mohammadhosseini, M.; Sarker, S.D.; Akbarzadeh, A. Chemical composition of the essential oils and extracts of achillea species and their biological activities: A review. J. Ethnopharmacol. 2017, 199, 257-315. [CrossRef] [PubMed]

6. Hachey, J.-M.; Collin, G.-J.; Gagnon, M.-J.; Simard, S.; Dufour, S.; Jean, F.-I.; Vernin, G.; Fraisse, D. Extraction and $\mathrm{gc} / \mathrm{ms}$ analysis of the essential oil of Achillea millefolium L. complex (compositae). J. Essent. Oil Res. 1990, 2, 317-326. [CrossRef]

7. Shawl, A.S.; Srivastava, S.K.; Syamasundar, K.V.; Tripathi, S.; Raina, V.K. Essential oil composition of Achillea millefolium L. growing wild in kashmir, India. Flavour Fragr. J. 2002, 17, 165-168. [CrossRef]

8. Jaimand, K.; Rezaee, M.B.; Mozaffarian, V. Chemical constituents of the leaf and flower oils from Achillea millefolium ssp. Elbursensis hub.-mor. From iran rich in chamazulene. J. Essent. Oil Res. 2006, 18, 293-295. [CrossRef]

9. Bocevska, M.; Sovová, H. Supercritical $\mathrm{CO}_{2}$ extraction of essential oil from yarrow. J. Supercrit. Fluids 2007, 40, 360-367. [CrossRef]

10. Falconieri, D.; Piras, A.; Porcedda, S.; Marongiu, B.; Goncalves, M.J.; Cabral, C.; Cavaleiro, C.; Salgueiro, L. Chemical composition and biological activity of the volatile extracts of achillea millefolium. Nat. Product Commun. 2011, 6, 1527-1530.

11. Mockute, D.; Judzentiene, A. Variability of the essential oils composition of achillea millefolium ssp. millefolium growing wild in lithuania. Biochem. Syst. Ecol. 2003, 31, 1033-1045. [CrossRef]

12. Orav, A.; Arak, E.; Raal, A. Phytochemical analysis of the essential oil of Achillea millefolium L. From various european countries. Nat. Product Res. 2006, 20, 1082-1088. [CrossRef] [PubMed]

13. Orav, A.; Kailas, T.; Ivask, K. Composition of the essential oil from Achillea millefolium L. from estonia. J. Essent. Oil Res. 2001, 13, 290-294. [CrossRef]

14. Todorova, M.; Konakchiev, A.; Tsankova, E. Chemical composition of the essential oils of three achillea species growing in bulgaria. Dokl. Bulga. Akad. Naukite 2001, 54, 25-28.

15. Adams, R.P. Identification of Essential Oil Components by Gas Chromatography/Quadrupole Mass Spectroscopy, 3rd ed.; Allured Publishing Corporation: Carol Stream, IL, USA, 2001.

16. Kondjoyan, N.; Bergdague, J.-L. A Compilation of Relative Retention Indices for the Analysis of Aromatic Compounds; Laboratoire Flaveur: Clermont-Ferrand, France, 1996.

17. Andrews, W. Manual of food quality control. 4. Rev. 1. Microbiological analysis. Food and drug administration. FAO Food Nutr. Pap. 1992, 14, 1-338. [PubMed] 
18. National Committee for Clinical Laboratory Standards (NCCLS). Methods for Dilution Antimicrobial Susceptibility Tests for Bacteria that Grow Aerobically; Approved Standard, 7th ed.; Clinical \& Laboratory Standards Institute: Wayne, PA, USA, 2006; Volume 26, pp. M7-A7.

19. Kindlovits, S.; Németh, É. Sources of variability of yarrow (Elt;i\&gt;achillea spp.) essential oil. Acta Aliment. 2012, 41, 92-103.

20. EL Kalamouni, C.; Raynaud, C.; Venskutonis, P.R.; Talou, T. Native vs. extracted essential oil: From chemical composition to biological activities. In Recent Advances in Food and Flavor Chemistry; Ho, C.-T., Mussinan, C., Shahidi, F., Contis, E.T., Eds.; Royal Society of Chemistry: London, UK, 2010; Volume 326, pp. 369-378.

21. Pattnaik, S.; Subramanyam, V.R.; Kole, C.R.; Sahoo, S. Antibacterial activity of essential oils from cymbopogon: Inter- and intra-specific differences. Microbios 1995, 84, 239-245. [PubMed]

22. Dorman, H.J.; Deans, S.G. Antimicrobial agents from plants: Antibacterial activity of plant volatile oils. J. Appl. Microbiol. 2000, 88, 308-316. [CrossRef] [PubMed]

23. Duru, M.E.; Cakir, A.; Kordali, S.; Zengin, H.; Harmandar, M.; Izumi, S.; Hirata, T. Chemical composition and antifungal properties of essential oils of three pistacia species. Fitoterapia 2003, 74, 170-176. [CrossRef]

(C) 2017 by the authors. Licensee MDPI, Basel, Switzerland. This article is an open access article distributed under the terms and conditions of the Creative Commons Attribution (CC BY) license (http://creativecommons.org/licenses/by/4.0/). 